\title{
LONG-DISTANCE OBSIDIAN TRADE IN INDONESIA
}

\author{
ROBERT H. TYKOT *, STEPHEN CHIA ** \\ *Department of Anthropology, U. of South Florida, Tampa, FL 33620, rtykot@luna.cas.usf.edu \\ **Pusat Penyelidikan Arkeologi Malaysia, Universiti Sains Malaysia, 11800 Penang, Malaysia
}

\begin{abstract}
Long-distance trade in obsidian from sources in the southwest Pacific has been well-documented for the Lapita culture complex, beginning about $1600 \mathrm{BC}$. Analyses of obsidian artifacts from recent excavations at Bukit Tengkorak in southeastem Sabah (Bomeo, Malaysia) indicate the use of obsidian from multiple sources in Melanesia as early as the 5th millennium BC. The archaeological presence of obsidian, up to more than $3500 \mathrm{~km}$ from its source, is the surviving evidence of what was almost certainly the longest Neolithic trade route in the world. In addition, these results indicate that long-distance trade networks existed in Indonesia at least 2500 years prior to the Lapita culture, and strengthen hypotheses of its origins in southeast Asia.
\end{abstract}

\section{INTRODUCTION}

Obsidian is a natural volcanic glass, typically of rhyolitic composition and without any significant crystalline structure, which was widely used for prehistoric stone tools because of its conchoidal fracture and extremely sharp cutting edges. Obsidian is formed only under certain geological conditions and the number of sources in a single geographic region which are suitable for stone tool manufacture is limited. The combination of a homogeneous chemical composition within individual obsidian sources and a restricted number of potentially exploitable sources almost always permits the confident attribution of an archaeological artifact to a single geological source using modern instnumental methods of elemental analysis, at least in regions where the geological sources are known and well-characterized. Numerous provenance studies of archaeological obsidian have demonstrated the long-distance 'trade' of this material while the resulting distribution patterns are usually interpreted in terms of prehistoric sociopolitical and economic systems [I]. Obsidian source lists and relevant information are maintained by the International Association for Obsidian Studies on the World Wide Web [2].

At least 66 obsidian sources exist in the southwest Pacific, and these have been studied, analyzed and catalogued over the last 20 years by J.R. Bird and his colleagues at the Australian Nuclear Science \& Technology Organisation's Lucas Heights Research Laboratories in Sydney [3-12]. Some obsidian sources were locally exploited as early as 20,000 BP; the most expansive use of obsidian, however, seems to have occurred during the period when Lapita voyagers colonized the eastem Melanesian and Polynesian islands and brought obsidian and pottery-making skills with them $[9,13]$. The distribution of obsidian from a 'homelands' area in New Britain and the Bismarck Archipelago, eastwards to Fiji [14], represents a linear distance of at least $3300 \mathrm{~km}$.

Lapita links to the west of New Guinea have been the subject of some debate, with some scholars favoring a predominantly Melanesian development of the Lapita culture, and others preferring a predominantly southeast Asian origin. Obsidian artifacts have been discovered at several sites in Indonesia (Bandung Plateau, Bogor, Besuki and Lake Leles in Java; Djambi and Lake Kerinci in Sumatra; Rundung Cave in Flores) and the Philippines (Rizal, Laguna, Bulacan, and Cavita Provinces) but appear to have come from local sources [15-19]. The lone exception is the rock- 
shelter site of Bukit Tengkorak in northern Bomeo, where Melanesian obsidian has been found in levels contemporary with the Lapita culture [20-21].

\section{ARCHAEOLOGICAL RESEARCH}

Test excavations in 1987 by P. Bellwood and P. Koon of the rock-shelter complex at Bukit Tengkorak ('Skull Hill'), on the coast $5 \mathrm{~km}$ south of Semporna in southeastem Sabah (Borneo, Malaysia), produced a total of 188 pieces of obsidian (total weight $58 \mathrm{~g}$ ) from a volume under 2 cubic meters, with 95 of the 99 pieces from secure stratigraphic contexts dating between about 900 and $400 \mathrm{BC}$ [20-21]. Of the 12 obsidian artifacts analyzed, 5 match the Talasea source (now known more precisely as the Kutau/Bao sub-source) in New Britain and 7 match a few artifacts from the Talaud Islands in Indonesia for which no geological source has yet been identified [22-23].

Further excavations were conducted in 1994 and 1995 by a joint Universiti Sains Malaysia and Sabah Museum team under the direction of S. Chia, with three additional trenches excavated at the rockshelter at the top of the hill, and three more about 30 feet below the rockshelter. In levels dating as early as $4300 \mathrm{BC}$, traces of Neolithic occupation were discovered. The inhabitants were probably an Austronesian-speaking people with origins in the Philippines, who may have lived in raised-floor houses, had domestic dogs, pigs, and chickens, and probably cultivated rice, millet, sugar cane, yams and other crops, although at Bukit Tengkorak they also consumed significant amounts of seafood judging from the mollusk and fish remains found there. They used polished stone adzes, the bow and arrow, and traveled in canoes, probably with outriggers and sails [24-25]. At Bukit Tengkorak, large clay deposits and abundant pottery wasters in open hearths were found, indicating that the site was a major prehistoric ceramic production center. 198 pieces of obsidian (total weight $60 \mathrm{~g}$ ) were also discovered, mostly in the form of tiny flakes less than $2 \mathrm{~cm}$ in length, along with occasional bladelets and a few exhausted core fragments. Since no obsidian sources are known to exist in Borneo, the simple presence of obsidian in such early contexts implied long-distance trade prior to the Lapita period, and the identification of the sources present at Bukit Tengkorak became of great significance for our understanding of Neolithic exchange systems in Malaysia and Indonesia.

\section{OBSIDIAN ANALYSIS}

Visual examination of the obsidian assemblage revealed examples ranging from black, highly translucent and very glassy, to grey-black, less glassy, and totally opaque, and each artifact was attributed to one of six visual types based on these characteristics. Fifteen samples each from trenches G17 (levels 13-26) and $\mathrm{J} 19$ (levels 12-24) were selected for analysis with all visual types represented. The electron microprobe, equipped with wavelength dispersive $\mathrm{X}$-ray spectrometers, was chosen for the analysis since this technique provides rapid, inexpensive and quantitative concentration data for all major and minor elements. A detailed description of the application of this technique to obsidian analysis has been published elsewhere and need not be repeated in its entirety here [26].

Only a small, $1 \mathrm{~mm}$ sized sample is required, so the method is minimally destructive. The samples were mounted in one-inch diameter epoxy disks and polished flat using a succession of finer grit grinding wheels and diamond paste, a process which is necessary to produce quantitative results and which also eliminates surface layers subject to chemical alteration by abrasion, leaching and hydration. After sputter-coating with carbon to prevent electrical charging, the samples were analyzed for 11 elements by the authors using the Cameca MBX microprobe located in the 
Department of Earth \& Planetary Sciences at Harvard University, using a $15 \mathrm{KeV}$ beam with a diameter of 40 microns. The $\mathrm{X}$-ray detectors were calibrated against pure mineral standards and a homblende reference material was repeatedly analyzed to insure inter-laboratory and inter-method comparability. Three different points on each sample were analyzed to protect against the potential heterogeneity of microlite inclusions. Two of the ninety measurements were rejected; the results for each sample were then averaged and normalized to $100 \%$ (Table I).

\section{DISCUSSION AND CONCLUSION}

Exploratory statistical and graphical examination of the data revealed that obsidian from at least three chemically distinct sources was utilized at Bukit Tengkorak (Figure 1). Group A consists of 17 samples, all of which belong to the very glassy, highly translucent visual types; group B consists of 12 samples, all but one of them less glassy, and less translucent or even opaque; one sample, also less glassy and totally opaque, represents group C. Careful comparison of our microprobe data with the Lucas Heights database $[7,27]$ indicates that group A matches the very well characterized Kutau/Bao (Talasea, New Britain) source, already known for its wide distribution in Melanesia (and also to Bukit Tengkorak) in the Lapita period. Group B matches the Talaud artifact group, defined by only a handful of specimens from the Talaud Islands and from the earlier excavations at Bukit Tengkorak. The single sample in group $\mathrm{C}$ comes from one of the Admiralty Islands (Lou Island) which consists of a succession of volcanic flows: three (Solang, Umrei, Wekwok) match group C. These three sources are extremely similar in their major/minor element composition, and the potential for slight differences between analytical methods warrants against a unique attribution until we have the opportunity to analyze sufficient source material ourselves.

Most of the Kutau/Bao samples come from later levels at Bukit Tengkorak (15 in levels 12-19; 2 in levels 22-24), while most of the Talaud group samples come from earlier levels ( 8 in levels $22-$ 24; 4 in levels 12-19), suggesting chronological changes in the relative importance of different obsidian sources. It has been argued that geographical proximity of archaeological site to geological source was the most important factor in earlier periods, while mobility patterns and social networks became of greater significance in later periods [10-11]. We must be cautious, however, in the interpretation of our Bukit Tengkorak data since the analyzed samples were not selected randomly from the overall assemblage. The single piece of Admiralty Island obsidian is from one of the later levels.

In conclusion, our findings demonstrate that long-distance, maritime trade networks existed between southeast Asia and Melanesia by the late 5th millennium BC. This suggests that at least one

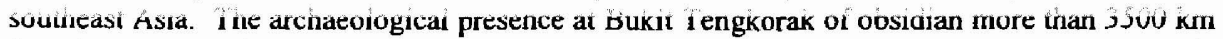
from its source is the surviving evidence of what was almost certainly the longest stone-age trade route in the world.

\section{ACKNOWLEDGMENT}

We thank David Lange for his assistance in operating the electron microprobe. 
Table I. Electron microprobe data for obsidian from Bukit Tengkorak.

\begin{tabular}{|c|c|c|c|c|c|c|c|c|c|c|c|c|c|}
\hline & el & $0_{2}$ & 10 & & & & & & & & & & [ot: \\
\hline $\mathrm{J} 19 / 445$ & 12 & 76.63 & 12.50 & 0.22 & 1.22 & 0.22 & 1.17 & 3.97 & 3.88 & 0.05 & 0.06 & 0.08 & 100.0 \\
\hline & & .78 & 12.54 & 0.23 & 1.19 & 0.21 & 4 & 3.90 & 3.89 & 0.02 & 0.05 & 0.04 & 100.0 \\
\hline & 12 & 72 & 12.56 & 0.23 & 1.2 & 0.22 & 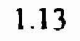 & 3. & 3.88 & 0.03 & 0.05 & 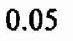 & 0.00 \\
\hline & 12 & 76.77 & 12.56 & 0.24 & 1.17 & 0.22 & 1 & 3.87 & 3.90 & 0.03 & 0.05 & 0.07 & 100.00 \\
\hline & 12 & 5.66 & 12.54 & 0.22 & 1.25 & 0.22 & 1.1 & 3.88 & 3.92 & 0.05 & 0.05 & 0.05 & 100.0 \\
\hline 17 & 13 & .72 & 12.57 & 0.23 & 1.15 & 0.22 & 1.16 & 3.89 & 3.88 & 0.03 & 0.06 & 0 & \\
\hline & 14 & 56 & 12.54 & 0.22 & 1.26 & 0.22 & 1.16 & 35 & 3.93 & 0.04 & 0.05 & 0.07 & 100.00 \\
\hline & 14 & 61 & 12.60 & 0.22 & 1.21 & 0.22 & 1.15 & 3.85 & 3.96 & 0.04 & 04 & 0.09 & 100.00 \\
\hline & 14 & 81 & 12.49 & 0.23 & 1.23 & 0.22 & 1.13 & 3.8 & 3.88 & 0.04 & 0.06 & 0. & 100. \\
\hline $17 / 313$ & 15 & 6.66 & 12.57 & 0.22 & 1.23 & 0.23 & 1.16 & 3.87 & 3.91 & 0.04 & 0.07 & 0.02 & 100 \\
\hline & 15 & 75 & 50 & 22 & 1.20 & 0.22 & 1.16 & 3.86 & 3.90 & 0.04 & 0.06 & 0.07 & 10 \\
\hline 17 & 17 & 76.69 & 12.58 & 0.24 & 1.19 & 0.22 & 1.14 & 3.84 & 3.92 & 0.05 & 0.06 & 0.08 & 100.00 \\
\hline 36 & 17 & 76.70 & 12.54 & 0.23 & 1.24 & 0.22 & 1.15 & 3.87 & 3.87 & 0.03 & 0.06 & 0.07 & 100.00 \\
\hline & 18 & 76.65 & 51 & 0.22 & 1.25 & 0.22 & 1.15 & 8 & .94 & 03 & 0.06 & 0.07 & 100.00 \\
\hline $7 / 2$ & 19 & 76.73 & 12.52 & 0.23 & 1.24 & 0.22 & 1.16 & 3.86 & 3.86 & 0.03 & 0.06 & 0.08 & 100.00 \\
\hline & 22 & 57 & 12.53 & 0.23 & 1.23 & 0.22 & 1.16 & 3.95 & 3.92 & 0.03 & 0.06 & 0.09 & 100.00 \\
\hline $9 / 2539$ & 24 & 75 & 12.45 & 0.22 & 1.22 & 0.22 & 1.13 & 3.94 & 3.89 & 0.04 & 0.05 & 0.07 & 100.00 \\
\hline
\end{tabular}

$\begin{array}{llllllllllllll}\text { Group A mean } & 76.70 & 12.54 & 0.23 & 1.22 & 0.22 & 1.15 & 3.89 & 3.90 & 0.04 & 0.06 & 0.07 & 100.00\end{array}$ $\begin{array}{lllllllllllll}\text { sd } & 0.06 & 0.04 & 0.01 & 0.03 & 0.00 & 0.01 & 0.04 & 0.03 & 0.01 & 0.01 & 0.02 & 0.00\end{array}$

\begin{tabular}{llllllllllllll}
\hline $\mathrm{J} 19 / 369$ & 14 & 71.64 & 14.68 & 0.19 & 1.78 & 0.10 & 0.77 & 4.94 & 5.76 & 0.02 & 0.11 & 0.00 & 100.00 \\
$\mathrm{~J} 19 / 3261$ & 15 & 71.26 & 14.91 & 0.21 & 1.69 & 0.10 & 0.79 & 5.06 & 5.86 & 0.03 & 0.08 & 0.00 & 100.00 \\
$\mathrm{G} 17 / 3112$ & 16 & 71.25 & 14.85 & 0.20 & 1.83 & 0.10 & 0.80 & 5.02 & 5.81 & 0.03 & 0.11 & 0.01 & 100.00 \\
$\mathrm{G} 17 / 1231$ & 18 & 71.31 & 14.84 & 0.20 & 1.80 & 0.11 & 0.79 & 5.01 & 5.80 & 0.03 & 0.10 & 0.02 & 100.00 \\
$\mathrm{~J} 19 / 3215$ & 23 & 70.58 & 15.23 & 0.25 & 1.73 & 0.13 & 0.83 & 5.19 & 5.93 & 0.03 & 0.09 & 0.00 & 100.00 \\
$\mathrm{~J} 19 / 3199$ & 23 & 71.36 & 14.69 & 0.20 & 1.90 & 0.10 & 0.79 & 5.02 & 5.81 & 0.03 & 0.09 & 0.01 & 100.00 \\
$\mathrm{~J} 19 / 2538$ & 24 & 71.70 & 14.59 & 0.18 & 1.90 & 0.09 & 0.80 & 4.93 & 5.66 & 0.01 & 0.10 & 0.02 & 100.00 \\
$\mathrm{G} 17 / 2648$ & 24 & 71.36 & 14.79 & 0.21 & 1.80 & 0.10 & 0.79 & 4.96 & 5.84 & 0.02 & 0.11 & 0.02 & 100.00 \\
$\mathrm{G} 17 / 949$ & 24 & 71.32 & 14.82 & 0.20 & 1.82 & 0.10 & 0.78 & 5.01 & 5.82 & 0.02 & 0.11 & 0.01 & 100.00 \\
$\mathrm{~J} 19 / 2521$ & 24 & 71.39 & 14.85 & 0.21 & 1.76 & 0.10 & 0.78 & 4.92 & 5.87 & 0.02 & 0.09 & 0.00 & 100.00 \\
$\mathrm{G} 17 / 2151$ & 25 & 71.30 & 14.90 & 0.21 & 1.73 & 0.09 & 0.76 & 4.98 & 5.90 & 0.03 & 0.10 & 0.01 & 100.00 \\
$\mathrm{G} 17 / 1383$ & 26 & 71.50 & 14.86 & 0.20 & 1.80 & 0.10 & 0.79 & 4.99 & 5.83 & 0.02 & 0.10 & 0.01 & 100.00 \\
\hline Group B mean & 71.33 & 14.83 & 0.21 & 1.80 & 0.10 & 0.79 & 5.00 & 5.82 & 0.02 & 0.10 & 0.01 & 100.00 \\
& sd & 0.27 & 0.15 & 0.02 & 0.06 & 0.01 & 0.02 & 0.07 & 0.06 & 0.00 & 0.01 & 0.01 & 0.00 \\
& & & & & & & & & & & & & \\
\hline J19/3049 & 15 & 72.80 & 13.78 & 0.30 & 2.44 & 0.24 & 1.14 & 4.98 & 4.13 & 0.04 & 0.06 & 0.08 & 100.00 \\
\hline Group C & & & & & & & & & & & & &
\end{tabular}




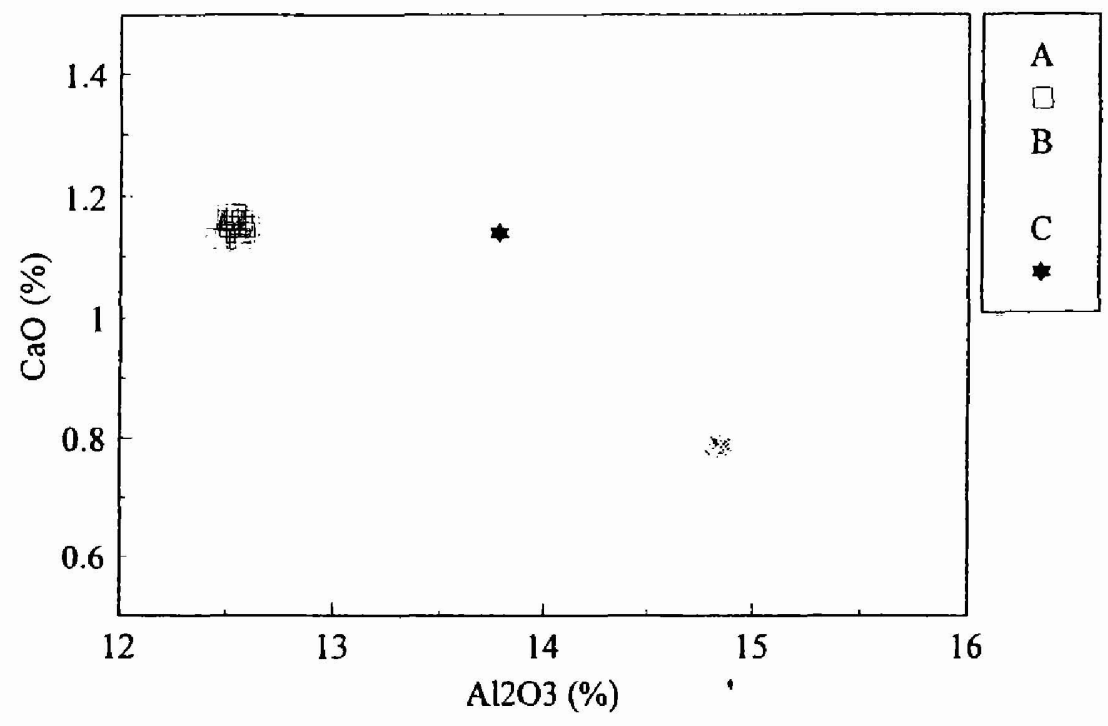

Figure 1. Bivariate plot of $\mathrm{Al}_{2} \mathrm{O}_{3}$ and $\mathrm{CaO}$ concentrations in obsidian from Bukit Tengkorak.

\section{REFERENCES}

1. C.E. Skinner and K.J. Tremaine, Obsidian: An Interdisciplinary Bibliography (International Association for obsidian Studies Occasional paper 1, 1993).

2. http://www.peak.org/obsidian/obsidian.html.

3. J.R. Bird, L.H. Russell, M.D. Scott and W.R. Ambrose, Analytical Chemistry 50, 2082-84 (1978).

4. P. Duerden, J.R. Bird, M.D. Scott, E. Clayton, L.H. Russell and D.D. Cohen, Nuclear Instruments and Methods 168, 447-452 (1980).

5. J.R. Bird, W.R. Ambrose, L.H. Russell and M.D. Scott, The Characterisation of Melanesian Obsidian Sources and Artefacts Using the Proton-induced Gamma-Ray Emission (PIGME) Technique (Report No. E/510, Australian Atomic Energy Commission, Lucas Heights, 1981).

6. J.R. Bird, P. Duerden, W.R. Ambrose and B.F. Leach, in Archaeological Studies of Pacific Stone Resources, edited by B.F. Leach and J. Davidson (British Archaeological Reports 104, Oxford, 1981), pp. 31-43.

7. P. Duerden, E. Clayton, J.R. Bird, W. Ambrose and F. Leach, in Archaeometry: Further Australasian Studies, edited by W.R. Ambrose and J.M.J. Mummery (Australian National University/Australian National Gallery, Canberra, 1987), pp. 250-260.

8. J.R. Bird and N. Shahgholi, in 7th Australian Conference on Nuclear Techniques of Analysis (Australian Institute of Nuclear Science and Engineering, 1991), pp. 110-113.

9. J.R. Bird, in La Pierre Préhistorique, edited by M. Menu and P. Walter (Laboratoire de Recherche des Musées de France, 1992), pp. 59-66. 
10. G.R. Summerhayes, J.R. Bird, M. Hotchkiss, C. Gosden, J. Specht, R. Torrence and R. Fullagar, in 8th Australian Conference on Nuclear Techniques of Analysis (Australian Institute of Nuclear Science and Engineering, 1993), pp. 107-109.

11. J.R. Bird, R. Torrence, G.M. Bailey and G. Summerhayes, in Sth Australasian Conference on Archaeometry (University of New England, Armidale, NSW, forthcoming).

12. G. Surnmerhayes, J.R. Bird, R. Fullagar, C. Gosden, J. Specht and R. Torrence, in Archaeological Obsidian Studies. Method and Theory, edited by M.S. Shackley (Plenum, New York, 1997).

13. G. Irwin, The Prehistoric Exploration and Colonisation of the Pacific (Cambridge University Press, 1992).

14. S. Best, Archaeology in Oceania 22, $21-32$ (1987).

15. H.-G. Bandi, in Suseestudien. Gedenkschrift zur Erinnerung an Felix Speiser, edited by H.-G. Gandi et al. (Museum fur Volkerkunde und Schweizerischen, Basel, 1951), pp. 127-161.

16. N.A. Subagas, Modem Quaternary Research in Southeast Asia 5, 35-41 (1979).

17. H.R. van Heekeran, The Stone Age of Indonesia (Nijhoff, The Hague, 2nd edition, 1972).

18. H.O. Beyer, Bulletin No. 29, National Research Council of the Philippines (Quezon City, 1948).

19. R.B. Fox, The Tabon Caves (National Museum Monograph 1, Manila, 1970).

20. P. Bellwood and P. Koon, Antiquity 63, 613-622 (1989).

21. P. Bellwood, Bulletin of the Indo-Pacific Prehistory Association 9, 122-161 (1989).

22. J.R. Bird, Bulletin of the Indo-Pacific Prehistory Association 9, 161-162 (1989).

23. P. Bellwood, Asian Perspectives 19, 240-288 (1976).

24. P. Bellwood, Journal of World Prehistory 1, 171-224 (1987).

25. P. Bellwood, Borneo Research Bulletin 24, 7-16 (1992).

26. R.H. Tykot, Joumal of Archaeological Science 24 (1997).

27. J.R. Bird, Pacific Obsidian Studies (Department of Prehistory, Research School of Pacific Studies, Australian National University, Canberra, forthcoming). 